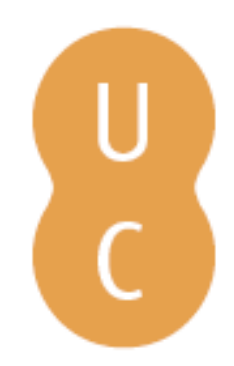

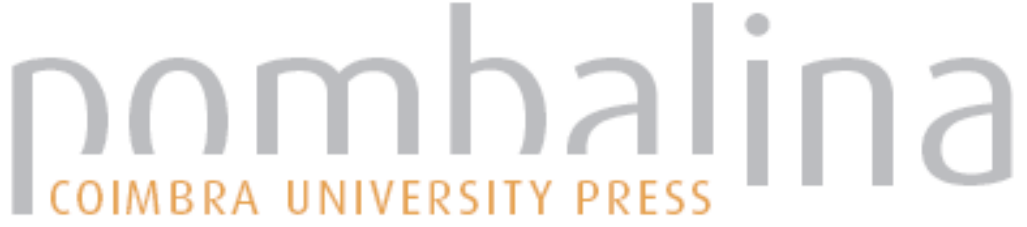

\section{Mudanças de paradigma na psiquiatria portuguesa}

Autor(es): $\quad$ Pereira, José Morgado

Publicado por: Imprensa da Universidade de Coimbra

URL

persistente: URI:http://hdl.handle.net/10316.2/31614

DOI: $\quad$ DOI:http://dx.doi.org/10.14195/978-989-26-0199-1_18

Accessed : $\quad$ 26-Apr-2023 07:53:27

A navegação consulta e descarregamento dos títulos inseridos nas Bibliotecas Digitais UC Digitalis, UC Pombalina e UC Impactum, pressupõem a aceitação plena e sem reservas dos Termos e Condições de Uso destas Bibliotecas Digitais, disponíveis em https://digitalis.uc.pt/pt-pt/termos.

Conforme exposto nos referidos Termos e Condições de Uso, o descarregamento de títulos de acesso restrito requer uma licença válida de autorização devendo o utilizador aceder ao(s) documento(s) a partir de um endereço de IP da instituição detentora da supramencionada licença.

Ao utilizador é apenas permitido o descarregamento para uso pessoal, pelo que o emprego do(s) título(s) descarregado(s) para outro fim, designadamente comercial, carece de autorização do respetivo autor ou editor da obra.

Na medida em que todas as obras da UC Digitalis se encontram protegidas pelo Código do Direito de Autor e Direitos Conexos e demais legislação aplicável, toda a cópia, parcial ou total, deste documento, nos casos em que é legalmente admitida, deverá conter ou fazer-se acompanhar por este aviso.

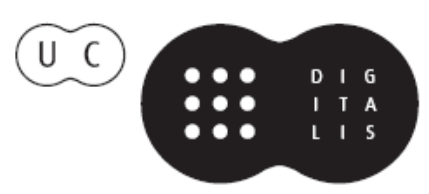


Maria Manuela Tavares Ribeiro

Coordenação

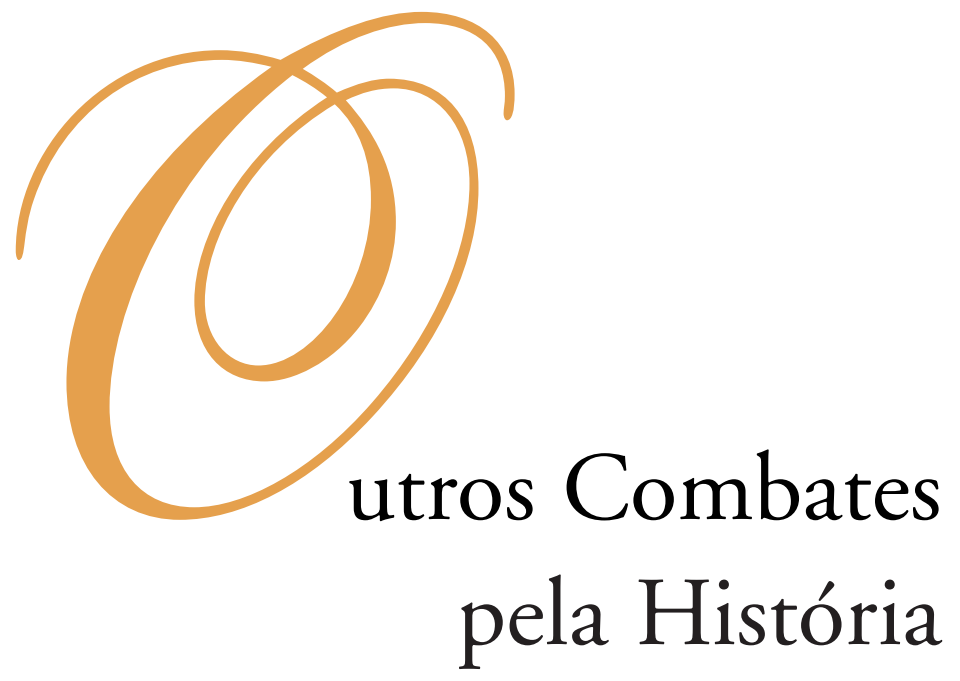




\section{COORDENAÇĀO EDITORIAL}

Imprensa da Universidade de Coimbra

Email: imprensauc@ci.uc.pt

URL: http://www.uc.pt/imprensa_uc

Vendas online: http://livrariadaimprensa.com

\section{CONCEPÇÃO GRÁFICA}

António Barros

\section{ORgANIZAÇĀO DOS TEXTOS}

Isabel Maria Luciano

Marlene Taveira

PRÉ-IMPRESSÃO

António Resende

Imprensa da Universidade de Coimbra

EXECUÇÃO GRÁFICA

SerSilito • Maia

ISBN

978-989-26-0041-3

DEPósito LEGAL

OBRA PUBLICADA COM O APOIO DE:

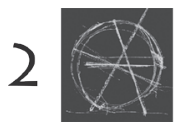

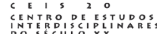

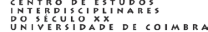

FCT Fundação para a Ciência e a Tecnologia

MINISTÉRIO DA CIÊNCIA, TECNOLOGIA E ENSINO SUPERIOR Portugal

Programa Operacional Ciência, Tecnologia, INOVAÇĀo DO QUADRo COMUNITÁRIO DE APOIO III

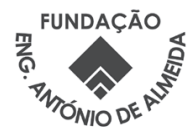

C JULHO 2010, IMPRENSA DA UNIVERSIDADE DE COIMBRA 
Maria Manuela Tavares Ribeiro

Coordenação

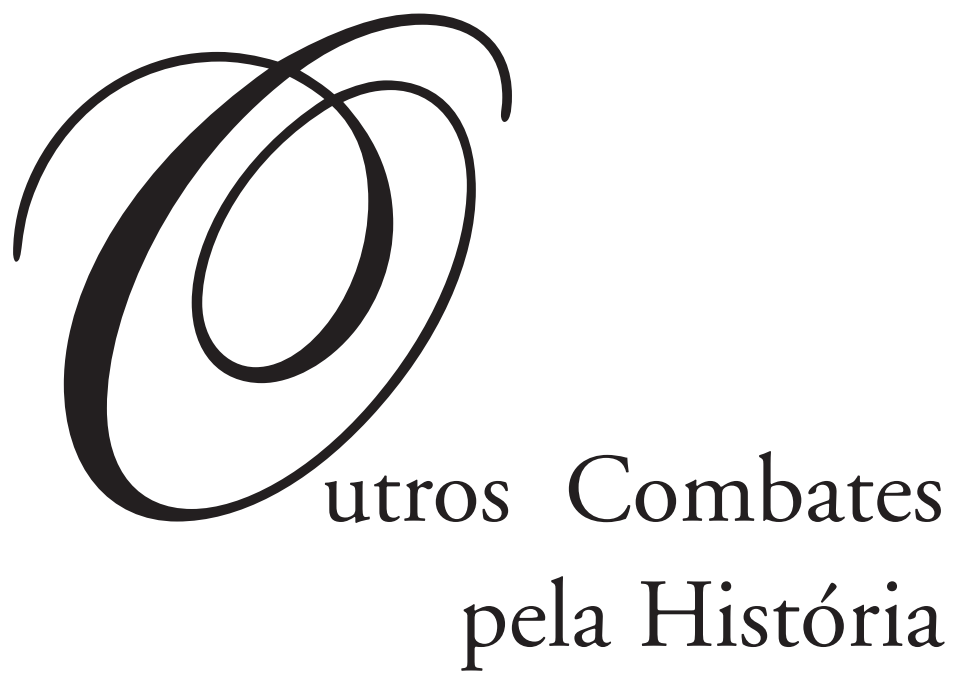

- colmbra 2010 
História e CiênCias 


\section{José Morgado Pereira}

\section{MUdANÇAS DE PARADIGMA NA PSIQUIATRIA PORTUGUESA}

Uma nota prévia sobre a génese do conceito de paradigma, para relembrar que as investigações de Thomas S. Kuhn provêm de disciplinas que ele dominava perfeitamente: a astronomia e a física teórica, precisamente dois exemplos de ciências do conhecimento rigorosas. Ora a psiquiatria, ramo da medicina, não é uma ciência, mas um conjunto articulado de dados semiológicos e clínicos correlacionados entre si e, sem dependência hierárquica, com um grupo heterogéneo de disciplinas, desde a anatomia e a neurofisiologia até à psiquiatria psicodinâmica e à psicologia experimental, sem esquecer os importantes contributos das ciências sociais. Salvaguardadas pois as especificidades e afastado o risco de extrapolaçôes simplistas e erróneas, podemos dizer, com Lanteri-Laura, que é manifestamente útil ao menos heuristicamente, tentar um exercício histórico/epistemológico, embora arriscado, utilizando este conceito de paradigma; Lanteri-Laura, a quem ouvi dizer que a psiquiatria é um saber, um saber-fazer e também um fazer-saber, citando Pierre Bourdieu e a sua "Teoria da Prática».

Regressemos aos primórdios do século XIX e à obra fundadora de Philippe Pinel (1745-1826), que no "Traité Medico-Philosophique sur L'alienation mental» escreveu que «A feliz influência exercida nos últimos tempos sobre a medicina pelo estudo das outras ciências, não permite já dar à alienação o nome de loucura, porque, dessa maneira, pode ter um alcance indeterminado e estender-se sobre todos os erros e confusão das que é susceptivel a espécie humana, o qual graças à debilidade e à depravação do homem, não teria limites. Deve-se então agrupar nesta categoria todas as ideias falsas e inexactas que formámos dos objectos, todos os erros salientes da imaginação e do juízo, tudo o que irrita ou provoca desejos fantásticos? Isso seria erigir-se em censor supremo da vida privada e pública dos homens, abarcar nessa perspectiva a história, a moral, a política e mesmo as ciências físicas...»

Compreende-se assim que nesse movimento conceptual Pinel fale de «alienação mental» e a distinga de um desvio jurídico ou ético da conduta, e a situe ao mesmo tempo como uma enfermidade, mas diferente de todas as outras, em particular das afecções simpáticas ou sintomáticas do cérebro, que deviam ser tratadas nos hospitais gerais, enquanto que a Alienação Mental só o deveria ser em estabelecimentos especializados para o seu Tratamento Moral.

O alienado ficava assim separado do criminoso e do delinquente, assim como dos enfermos tributários da medicina geral, organizado em torno da escola de Paris e suas 
instituições hospitalares. A alienação era uma enfermidade única, que podia ter várias apresentaçôes sindrómicas, cuja semiologia distinta devia ser reconhecida a fim de as distinguir de outras enfermidades. A alienação mental apresentava assim quatro formas semiológicas típicas (o idiotismo, a demência, a mania e a melancolia).

Este primeiro período vai do fim do século das Luzes até meados do século XIX (paradigma da alienação mental) quer na tradição psiquiátrica francesa, germânica, italiana ou inglesa. Facto central deste período é também a construção dos Asilos ${ }^{1}$.

A crítica de Jean-Pierre Falret à concepção de alienação mental de Pinel e Esquirol, inaugura o novo período, ou "paradigma das doenças mentais». Vai surgindo a distinção de certo número de afecções irredutíveis entre si, e cujo conjunto escapa à unidade ou unificação, e que vai até aos anos 20 do século XX. Todo este período pode também ser designado como de Naturalismo Psiquiátrico. O edifício mais perfeito que coroa o período paradigmático das doenças mentais foi levado a cabo por Emil Kraepelin (1856-1926) ${ }^{2}$.

As doenças mentais são pois espécies mórbidas naturais, irredutíveis entre si. Começa a defender-se a necessidade de fazer reentrar a psiquiatria na medicina, há uma clara medicalização ou apropriação médica nalguns casos discutível, como por exemplo a propósito das perversões ou do suicídio. Tratava-se de uma posição doutrinal, pois continuavam a edificar-se asilos, e só após a I Guerra Mundial surgem os primeiros serviços abertos. Há diferenciações no tratamento, indicações e contra-indicações. Alguns medicamentos acalmavam a angústia e surgem depois os anti-epilépticos e os hipnóticos. O trabalho era utilizado para a prosperidade das instituiçôes, mas alguns autores, como Herman Simon começam a dar-lhe finalidade terapêutica.

Em Portugal este é o período dos grandes alienistas, que desenvolveram e consolidaram a psiquiatria e a sua institucionalização (Miguel Bombarda, Júlio de Matos, Magalhães Lemos, Sobral Cid).

Este segundo paradigma das doenças mentais começa a entrar em crise para os finais dos anos 20: critica-se a atitude semiológica dos clássicos e a multiplicação de espécies mórbidas. Algumas grandes personalidades tinham sido arautos de novas visões da psicopatologia, e são figuras de transição para o terceiro paradigma (Freud, Janet, Bleuler, Jaspers). Começa a impôr-se mercê de influências diversas e cruzadas, convergentes e às vezes antagonistas, um novo paradigma dito das "grandes estruturas psicopatológicas»: a psicologia da forma (gestalt), a neurologia globalista, a filosofia fenomenológica, a psicanálise. Há um certo retorno à unidade embora com subdivisões inevitáveis, sendo a polarização principal à volta da dicotomia estruturas neuróticas versus estruturas psicóticas. Há uma nova relação entre história e estrutura e a introdução de novos autores das ciências humanas e da filosofia, de que são exemplo as figuras de Minkowski, Kretschmer e Henri Ey; (Minkowski utilizando o pensamento de Bergson, Kretschmer, o Neo-Kantismo, Henri Ey cujo organodinamismo tenta conciliar a obra do neurologista H. Jackson com a psicanálise de Freud e outros autores da escola alemã e francesa).

\footnotetext{
${ }^{1}$ Entre nós o melhor representante deste período é o médico Bernardino António Gomes (filho).

${ }^{2}$ Houve excepçôes e resistências. Morel (1809-1873), o autor do Tratado das Degenerescências manteve-se fiel à concepção da unidade absoluta da alienação mental. Interessado em aspectos etiológicos, deve em parte a Lamarck a influência para a sua obra, que é claramente pré-darwiniana.
} 
Em Portugal, Barahona Fernandes é o maior representante deste terceiro paradigma. A psicopatologia toma agora uma importância central. Incrementam-se as terapias físicas por um lado, mas por outro desenvolvem-se a psicanálise, a sugestão e a hipnose, diversificam-se as técnicas terapêuticas, incluindo terapias de grupo, o psicodrama e mais tarde os psicofármacos. Também surge mais tarde a influência das ciências sociais, nomeadamente após a II Guerra Mundial. Este terceiro grande período estende-se até final dos anos 60, surgindo depois um conjunto muito diversificado de orientações e influências intrínsecas mas também extrínsecas à Psiquiatria.

Em Portugal, a grande figura da reforma na organização, legislação e ensino oficial da Psiquiatria é Júlio de Matos (1856-1922), também o maior tratadista da Psiquiatria Portuguesa. Positivista, e alienista-filósofo nas palavras de Barahona Fernandes, fundador com Teófilo Braga da revista "O Positivismo», republicano (do sector mais conservador do republicanismo português), delineou a construção do Hospital que leva o seu nome, inaugurado muito mais tarde.

Num trabalho de 1908 em que faz um balanço sobre a psiquiatria em Portugal de singular clareza, diz a certa altura num trecho fundamental para o tema que tratamos: «No louco vemos o doente que Pinel dignificou, não vemos o agente degenerativo que a psiquiatria contemporânea pôs em relevo». E parte para exemplificaçôes significativas do seu pensamento: «a hospitalização dos alienados não é só um problema de beneficência; é ainda e sobretudo, um problema de defesa social, cuja solução incumbe aos governos e não pode confiar-se aos exclusivos sentimentos individuais»; e depois «na França, Bélgica, Itália, Alemanha sobretudo, a hospitalização oficial de alienados progride incessantemente, com uma especialização que todos os dias se afirma"; outro exemplo: "muitos crimes são obra sua; e a procriação destes seres anormais constitui, mercê da herança, uma das causas mais poderosas da degenerescência das raças. Se a piedade nos compele a protegê-los, os interesses superiores da espécie obrigam-nos a evitar o seu convívio». A hospitalização seria para Júlio de Matos a medida que harmonizava estas duas ordens de impulsos na aparência contraditórios, «sendo para o louco um abrigo e inigualável meio de tratamento, o manicómio é para a sociedade o único instrumento eficaz de defesa». Percebe-se claramente a reconversão da teoria da degenerescência tornada uma espécie de determinismo ou fatalidade biológica, acusando já a influência de autores como Spencer, Lombroso e uma certa leitura de Darwin. Denunciando o facto de não existir ensino oficial da Psiquiatria em 1908, enfatizava a necessidade de «se partirem os moldes espiritualistas da psicologia tradicional». Nos outros alienistas como Magalhães Lemos, Miguel Bombarda ou Bettencourt Rodrigues, encontramos a mesma concepção geral da hospitalização de alienados. Em tom mais moderado e neutro em Magalhães Lemos, mais radical e emocionalmente carregado em Bombarda, ao definir o manicómio como devendo ser ao mesmo tempo asilo, prisão, oficina, laboratório, quartel e hospital. Não se tratava só do corolário de uma era pré-psicofarmacológica como por vezes se diz, mas também consequência lógica de concepções psiquiátricas decorrentes de princípios filosóficos naturalistas, de várias matizes.

Por razões ideológicas, circunstâncias sociais e políticas, e influências científicas que precisam de ser estudadas, os alienistas portugueses, neste período de consolidação científica e organizativa da especialidade, ficaram mais próximos de autores como Krafft-Ebing, Magnan e Eugénio Tanzi, isto é, dos maiores arautos e difusores das 
ideias de degenerescência na psiquiatria, e muito menos de figuras mais pura e simplesmente clínicas como Chaslin, Seglas e mesmo Ballet e Ball, que criticavam a extensão excessiva do conceito de degenerescência ou manifestavam fundadas reservas à sua validade conceptual.

Quanto a Sobral Cid (1877-1941) que sucedeu a Júlio de Matos na cátedra de psiquiatria em Lisboa em 1923, a sua obra é de transição entre o segundo e o terceiro período paradigmático porque nele se repercutem influências de autores e disciplinas que representam o apogeu do segundo paradigma e outros que iniciam o afastamento progressivo desta concepção. Quando num trabalho de 1924 considera que se atinge a compreensão científica de uma psicose quando chegamos à inteligência psicológica dos actos do alienado consideradas como manifestação de uma personalidade e das suas reacções sobre o meio, colocando-a a par e em paralelo com a explicação causal em termos anatomo-fisiológicos, ou quando afasta de forma inquestionável o conceito de degenerescência, opera um passo fundamental na direcção da psiquiatria moderna e na ultrapassagem do naturalismo psiquiátrico.

Trata-se também de um começo de compreensão da mente do paciente: superação da redução biológica naturalista com integração da dimensão psicológica, com a aceitação dos mecanismos psicológicos de defesa, procura da compreensibilidade dos sintomas, e o sublinhar do papel da afectividade. A partir daí constitui-se uma escola de psicopatologia com repercussões assistênciais e na prática institucional. Embora aceite unidades asilares para os totalmente inválidos e colónias agrícolas, Sobral Cid defende a localização do hospital psiquiátrico na cidade universitária, os serviços abertos, a ocupação e o divertimento dos doentes, a assistência social e a assistência familiar. Frente à filosofia «institucionalizadora» dos seus antecessores, anote-se a atenção à identidade individual dos pacientes e à sua preservação com exemplos de textos publicados entre 1927 e 1931; «a assistência psiquiátrica contemporânea, longe de propugnar pelo asilamento sistemático de todos os alienados, tem antes por objectivo dominante evitar na medida do possível o seu internamento, e quando ele se torna necessário, reduzir ao mínimo a sua duração». E «a nota dominante deste movimento evolutivo da assistência psiquiátrica é a tendência comum a todos os países cultos, a resolver o antigo complexo asilar num conjunto de organismos ou institutos de assistência nitidamente diferenciados e tendo em vista respectivamente a terapêutica, a profilaxia e a revalorização social do alienado». Ou ainda quando insiste na adopção de um regime individual, menos rigoroso no internamento e a defesa do open-door. Insiste igualmente na defesa do trabalho do serviço social, estabelecendo um contacto regular «e relações seguidas entre corpo clínico, doente e família, no sentido da revalorização social e pragmática dos doentes».

Sobre o universo asilar já não há grandes entusiasmos ou ilusões como se constata; «a praxe asilar mostra-nos que o internamento prolongado do esquizofrénico, longe de ter qualquer utilidade, lhe é em regra extremamente nocivo, pois que, favorecendo as tendências autistas, de certo modo consolida a sua desinserção do mundo real» e noutro trecho, "especialmente destinado a assegurar o internamente prolongado, muitas vezes definitivo dos doentes que lhe eram confiados, o asilo tendia naturalmente a converter-se numa espécie de depósito ou albergue de alienados». Daqui resulta a indicação imperativa de alta precoce ou antecipada, acrescenta. 
Concluindo, a psiquiatria é o ramo da medicina em que a complexidade epistemológica e a presença dos valores está particularmente presente e de forma aguda. O grau de abstracção que requer a análise dos factos e dos valores em psiquiatria, o seu papel essencial na teoria e as suas decisivas aplicações práticas, e ainda a profunda relação que há entre uns e outros, torna necessária uma reflexão profunda e contínua sobre o rigor metodológico na avaliação dos factos clínicos e a complexa teia de valores que inevitavelmente os impregnam.

\section{BIBLIOGRAFIA}

Berrios, German E. - The History of Mental Symptoms. Cambridge University Press. 1996.

Bynum, W.F.; PORTER, Roy; SHePherd, Michael - The Anatomy of Madness. Tavistock, London. 1985.

CID, J. M. Sobral - Obras. Fundação Calouste Gulbenkian, vol. 1/2. Lisboa. 1983/84.

FERNANDES, Barahona - A Psiquiatria em Portugal. Roche, Lisboa. 1984.

Lantéri-Laura, G. - Psychiatrie et Connaissance; Sciences en Situation, Paris. 1991.

—, Essai sur les Paradigmes de la Psychiatrie Moderne; Editions du Temps, Paris. 1998.

MATOS, Júlio de - Os Alienados em Portugal in «Notas sobre Portugal», vol. 1. Imprensa Nacional. Lisboa. 1908.

Micale, Mark S.; PORTER, Roy - Discovering the History of Psychiatry. Oxford University Press. 1994.

Pereira, J. Morgado - Institucionalização e Reorientação da Psiquiatria Portuguesa nas Primeiras décadas do século XX. In «Estudos do século XX; n. ${ }^{\circ} 5$ - Ciência, Saúde e Poder. Ariadne Editora, Coimbra. 2005.

PINEL, Philippe - Traité Médico-Philosophique sur L'Aliénation Mentale; 2a Edição. Paris. 1809.

POSTEL, Jacques - Élements pour une Histoire de la Psychiatrie Occidentale. L'Harmattan, Paris. 2007. 
Série

Documentos

Imprensa da Universidade de Coimbra

Coimbra University Press

2010

- U

C • 